\title{
Pesquisas produzidas no Brasil sobre educação e cidadania: um estudo do tipo estado da arte
}

\author{
Assis Leão da Silva ${ }^{1}$ \\ José Nildo Alves Caú2 \\ Maria Dayana Lopes de Oliveira ${ }^{3}$
}

\begin{abstract}
RESUMO
O artigo se propõe a identificar as problematizações realizadas no Brasil, nos anos de 2014 a 2018, quanto à temática educação e cidadania, com a finalidade de mapear o estado da arte e apresentar as contribuições dos trabalhos analisados. O estudo se caracteriza como uma pesquisa bibliográfica. Os trabalhos examinados, 7 teses e 10 dissertações, foram obtidos por meio de consulta à Biblioteca Digital Brasileira de Teses e Dissertações. O estado da arte, nesse artigo, foi dividido em dois momentos. Primeiramente, foram analisados os dados objetivos dos trabalhos selecionados, por meio da identificação e quantificação desses dados. No segundo momento, foram realizados os aprofundamentos das teses e dissertações. Os resultados revelaram, dentre outras coisas, um número reduzido de pesquisas, denotando a necessidade de novas problematizações quanto ao tema proposto, especialmente articuladas aos interesses da juventude.
\end{abstract}

PALAVRAS-CHAVE: Estado da Arte. Educação. Cidadania. Juventude.

State of the art: dissertations and theses published in Brazil that discuss education and citizenship

\begin{abstract}
The article may request the identification of problems in Brazil, in the years 2014 to 2018, regarding the theme education and citizenship, with the use of
\end{abstract}

\footnotetext{
${ }^{1}$ Doutor em Educação (UFPE). Professor (IFPE), Recife, Pernambuco, Brasil. Orcid: https://orcid.org/0000-00025926-652X. E-mail: assisleao33@gmail.com.

${ }^{2}$ Doutor em Educação (UFPE). Professor (IFPE), Recife, Pernambuco, Brasil. Orcid: https://orcid.org/0000-00028963-0134. E-mail: caunildo@gmail.com.

${ }^{3}$ Mestranda em Educação Profissional e Tecnológica (PROFEPT - IFPE). Auditora (IFPE), Barreiros, Pernambuco, Brasil. Orcid: https://orcid.org/0000-0003-1918-7592. E-mail: dayana2804@ gmail.com.
} 
mapping or the state of the art and displaying as contributions of the analyzed studies. The study is characterized as a bibliographic search. The examined papers, 7 theses and 10 dissertations, were examined by consulting the Brazilian Digital Library of Dissertations and Theses. The state of the art, in this article, was divided into two moments. First, the data of the selected objectives were analyzed, through the identification and quantification of these data. In the second moment, the theses and dissertations were further developed. The results revealed, among other things, a small number of researches, denote the need for new problems regarding the proposed theme, especially linked to the interests of youth.

KEYWORDS: State of the Art. Education. Citizenship. Youth.

Estado del arte: disertaciones y tesis publicadas en Brasil sobre educación y ciudadanía

\section{RESUMEN}

El artículo puede solicitar la identificación de problemas en Brasil, en los años 2014 a 2018, con respecto al tema educación y ciudadanía, con el uso del mapeo o el estado del arte y mostrando como contribuciones de los estudios analizados. El estudio se caracteriza como una búsqueda bibliográfica. Los trabajos examinados, 7 tesis y 10 disertaciones, fueron examinados consultando a la Biblioteca Digital Brasileña de Disertaciones y Tesis. El estado del arte, en este artículo, se dividió en dos momentos. Primero, se analizaron los datos de los objetivos seleccionados, mediante la identificación y cuantificación de estos datos. En el segundo momento, las tesis y disertaciones se desarrollaron aún más. Los resultados revelaron, entre otras cosas, un pequeño número de investigaciones que denotan la necesidad de nuevos problemas con respecto al tema propuesto, especialmente relacionado con los intereses de los jóvenes.

PALABRAS CLAVE: Estado del Arte. Educación. Ciudadania. Juventud.

$* * *$

\section{Introdução}

O presente artigo tem o propósito de identificar as problematizações realizadas no Brasil, nos anos de 2014 a 2018, quanto à temática educação e 
cidadania, com a finalidade de mapear o estado da arte e apresentar as contribuições dos trabalhos analisados.

$\mathrm{O}$ interesse por essa temática surgiu diante do desafio de uma educação voltada à cidadania, que seja capaz de promover a formação de cidadãos críticos e implementadores de mudanças, capazes de reivindicar seus direitos e intervir na realidade para transformá-la.

De início, cabe destacar que o conceito de cidadania ganha destaque no âmbito das revoluções burguesas, especialmente, com a Revolução Francesa de 1789. Conforme Pacheco (2015), a burguesia era enriquecida, porém excluída de direitos sociais e políticos pela aristocracia decadente, por isso, ela assume a luta pela igualdade de direitos.

\begin{abstract}
Essa luta pela cidadania plena resumia-se, basicamente, em liberdade (direitos políticos), igualdade (direitos sociais) e propriedade (direitos econômicos). Somente a concretização dessas três dimensões caracteriza a cidadania plena. (PACHECO, 2015, p. 30).
\end{abstract}

Nesse sentido, sabe-se que o direito à educação é imprescindível para alcançar os demais direitos. Assim, "a ausência de uma população educada tem sido sempre um dos principais obstáculos à construção da cidadania civil e política.” (CARVALHO, 2002, p. 11).

Ademais, torna-se essencial possibilitar plena formação cidadã articulada aos interesses da juventude brasileira, filha da classe trabalhadora. Essa realidade tem provocado o desafio de apreender e reconhecer que o jovem que chega à escola traz toda a sua experiência produzida nos múltiplos espaços da sociedade. Em contrapartida, ao entrar no contexto escolar, é normalmente submetido ao processo de formação homogeneizada que visa regular os comportamentos e condições de ensinoaprendizagem, conforme apresenta Caú (2017).

Visando romper com a visão do processo de formação de homogeneização, "os estudos socioculturais ressaltam a diversidade na forma de expressão da juventude (culturas juvenis) e salientam a 
diversidade do que é juvenil (identidades juvenis)". (ALPÍZAR; BERNAL, 2005, p. 28). Deste modo, o jovem passa a ser visto como parte de um grupo social que partilha desejos, vontades e propósitos e, portanto, carece de oportunidade para vivenciar e intercambiar um acervo de experiências de modo a ampliar suas condições de escolha (CAÚ, 2017).

A esse respeito, Carrano e Martins (2011) relatam a necessidade da instituição escolar e de seus professores abrirem espaços de escuta para compreensão das identidades e comportamentos da juventude.

Através da elaboração de linguagens em comum, a escola pode recuperar seu prestígio entre os jovens, bem como o prazer deles estarem em um lugar que podem chamar de seu na medida em que são reconhecidos como sujeitos produtores de cultura. (p. 54).

Nesse contexto, como observado por Dayrell, Leão e Reis (2007), a condição de aluno é uma alternativa que poderá ser ou não incorporada pelo jovem. Por essa razão, implicações nas relações da escola de ensino médio e os jovens/alunos, por exemplo, refletem a ausência de canais de escuta como um dos fatores do distanciamento dos jovens e da escola.

Esta ausência de canais de escuta contribui na insuficiente ligação entre o processo formativo e as reais necessidades e interesses da juventude, refletindo na baixa participação dos estudantes nos processos decisórios. Em face disso, torna-se imprescindível a busca pela superação do pouco, ou até mesmo ausente, diálogo nas tomadas de decisões relativas ao contexto escolar. Dessa forma, diante da finalidade social da escola, deve se propor uma formação que estimule a vivência da cidadania nesse ambiente.

Nessa perspectiva, ao reconhecer o afastamento, na vivência do cotidiano escolar, entre a assertiva da reflexão e a vivência de práticas significativas, mostra-se a possibilidade de aproximar os interesses dos jovens das finalidades propostas para essa etapa tão importante na formação das juventudes (DAYRELL, LEÃO e REIS, 2007; KRAWCZYK, 2009). 
Deste modo, a escola ao ser repensada para além da ideia de um mecanismo de seleção, se apresenta como um espaço de socialização, participação, diálogo e trocas de convivências entre gerações. Reconhecendo a juventude que a constitui e incorporando sua cultura.

À vista disso, tornam-se cada vez mais significativas as formas de participação e as definições dos rumos que interferem na construção dos projetos de vida de milhares jovens brasileiros. Contribuindo, dessa forma, na direção de processos formativos sistemáticos no estímulo à autodeterminação dos estudantes em busca da cidadania plena legitimada.

Assim, faz-se necessário que os espaços pedagógicos, sejam eles formais ou não formais, possibilitem a participação e a liberdade de opinião. Pois, Gadotti (1993) destaca que a educação para a cidadania não pode ser limitada a uma grade horária, ou seja, não é incutir um modelo para que os alunos o levem pela vida afora, ela deve ser colocada em prática no ambiente escolar.

Nesse sentido, Gadotti (2014, p. 4) defende que "Nos formamos para a participação participando, enfrentando os desafios técnicos e políticos da participação. A participação é conquista políticopedagógica.”. Portanto, deve-se promover a organização do espaço pedagógico de modo a possibilitar a efetiva participação dos estudantes, uma vez que através disso eles podem desenvolver uma consciência crítica sobre o papel que ocupam na sociedade.

Conforme Caú (2017), a escola atua como importante instituição na socialização da juventude e na formação das novas gerações. Por isso, tem o desafio atual de promover estratégias de participação e tomada de decisão que tornem o processo de aprendizagem significativo para os estudantes, mesmo diante das adversidades do modo de produção vigente.

Assim, vale ressaltar a importância de um processo formativo que prime por uma educação de qualidade, democrática e que seja significativa para a grande maioria dos filhos da classe trabalhadora que frequenta a escola brasileira. A esse respeito, ressalta-se, ainda, que essa educação deve se aproximar dos interesses e das necessidades efetivas dos estudantes, 
especialmente dos jovens, considerando que normalmente os currículos, conteúdos programáticos, apresentam pouca relação com os seus interesses. Sobre isso, conforme Carrano (2010, p. 145) os jovens "denunciam que o que lhes é oferecido como conhecimento se apresenta de pouca praticidade para os desafios que precisam enfrentar no mundo do trabalho".

A partir desse panorama, foram selecionadas as dissertações e teses que dialogavam com a abordagem proposta pela pesquisa realizada e apresentada neste artigo. Primeiramente, foram mapeados e analisados os dados objetivos dos trabalhos selecionados, através da quantificação e de identificação de dados bibliográficos. Posteriormente, foram realizadas leituras aprofundadas desses trabalhos com a finalidade de apresentar suas contribuições, a partir das problemáticas, das conclusões e de outras observações pertinentes.

\section{Percurso metodológico}

O trabalho desenvolvido se caracteriza como uma pesquisa bibliográfica, pois, conforme Gil (2008), esse tipo de pesquisa se fundamenta nas contribuições de vários autores sobre determinado assunto. Dessa forma, os trabalhos denominados de estado da arte resultam de uma pesquisa bibliográfica e, conforme Ferreira (2002), apresentam uma metodologia de caráter inventariante e descritivo sobre o tema que se propõe investigar.

Assim, destaca-se a relevância do estado da arte para identificar as problemáticas já realizadas na literatura acadêmica e, dessa forma, apontar as aproximações entre elas e as lacunas a serem investigadas. Ademais, conforme Marconi e Lakatos (2011), a citação das principais conclusões a que outros autores chegaram possibilita evidenciar a contribuição da pesquisa realizada.

Os trabalhos foram selecionados a partir da consulta a Biblioteca Digital Brasileira de Teses e Dissertações (BDTD) que “integra e dissemina, em um só portal de busca, os textos completos das teses e dissertações defendidas nas instituições brasileiras de ensino e pesquisa”. (BDTD, 2019) 
Este repositório, criado em 2002, é coordenado pelo Instituto Brasileiro de Informação em Ciência e Tecnologia (IBICT). Atualmente, conta com 116 instituições participantes, dispõe de 152.525 teses e 422.244 dissertações, cujo acesso é livre de quaisquer custos. (BDTD, 2019)

No levantamento bibliográfico, realizado até julho de 2019, foram utilizados os seguintes parâmetros para mapeamento das dissertações e teses: a) fonte: Biblioteca Digital Brasileira de Teses e Dissertações; b) descritor utilizado: "educação e cidadania"; c) idioma: português; d) período de publicação: anos 2014 a 2018.

A delimitação do período a partir de 2014 justifica-se pela publicação da Lei $\mathrm{n}^{\circ}$ 13.005/2014 que aprovou o Plano Nacional de Educação (PNE). O PNE traz dentre suas diretrizes, apresentadas no art. $2^{\circ}$, a "V - formação para o trabalho e para a cidadania, com ênfase nos valores morais e éticos em que se fundamenta a sociedade", bem como a "VI - promoção do princípio da gestão democrática da educação pública". (BRASIL, 2014)

Além disso, a Lei $\mathrm{n}^{0}$ 12.852/2013 (em vigência no ano de 2014), que instituiu o Estatuto da Juventude, apresenta no seu capítulo II, que trata sobre os direitos dos jovens, a seção 1: "Do Direito à Cidadania, à Participação Social e Política e à Representação Juvenil". (BRASIL, 2013)

A referida lei, no art. $4^{\circ}$ - parágrafo único, entende por participação juvenil "I - a inclusão do jovem nos espaços públicos e comunitários a partir da sua concepção como pessoa ativa, livre, responsável e digna de ocupar uma posição central nos processos políticos e sociais;". (BRASIL, 2013)

Assim, considerando a definição dos parâmetros, a busca resultou em 47 trabalhos. Em seguida, foram analisadas as dissertações e teses tomando como base seus respectivos títulos e resumos. A partir disso, foram definidos, para seleção dos trabalhos, critérios de exclusão tendo em vista que o presente artigo tem como foco a cidadania em sua dimensão política. 
Nessa perspectiva, foram desconsiderados os trabalhos que versaram sobre cidadania no âmbito ambiental, social, cultural e também os que tiveram como objeto de estudo outro país que não fosse o Brasil. Assim, foram classificados 17 trabalhos, sendo 7 teses e 10 dissertações.

\section{Panorama dos dados bibliográficos}

Nessa seção do artigo, serão mapeados e analisados os dados objetivos dos trabalhos selecionados. Desse modo, haverá, conforme Ferreira (2002), a interação com a produção acadêmica através da quantificação e de identificação de dados bibliográficos, com a finalidade de mapear os trabalhos num período delimitado, em anos, locais, áreas de produção.

Ante o exposto, os 17 trabalhos selecionados foram catalogados em um editor de planilhas, considerando os seguintes dados: título, curso, ano, instituição de origem, estado da federação, região, temática e metodologia. Com base nisso, foi possível a construção de alguns delineamentos analíticos, por meio de gráficos, conforme é possível verificar a seguir:

Gráfico 1 - Distribuição dos trabalhos selecionados por ano e tipo de publicação

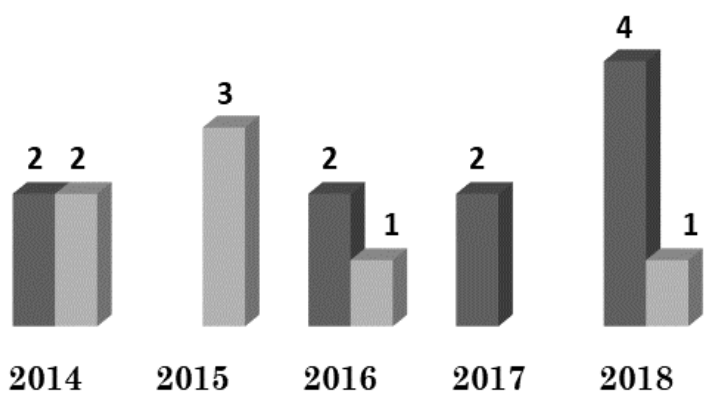

- Dissertação $\quad$ Tese

Fonte: Autoria própria 
Gráfico 2 - Distribuição dos trabalhos selecionados por estado e região do Brasil

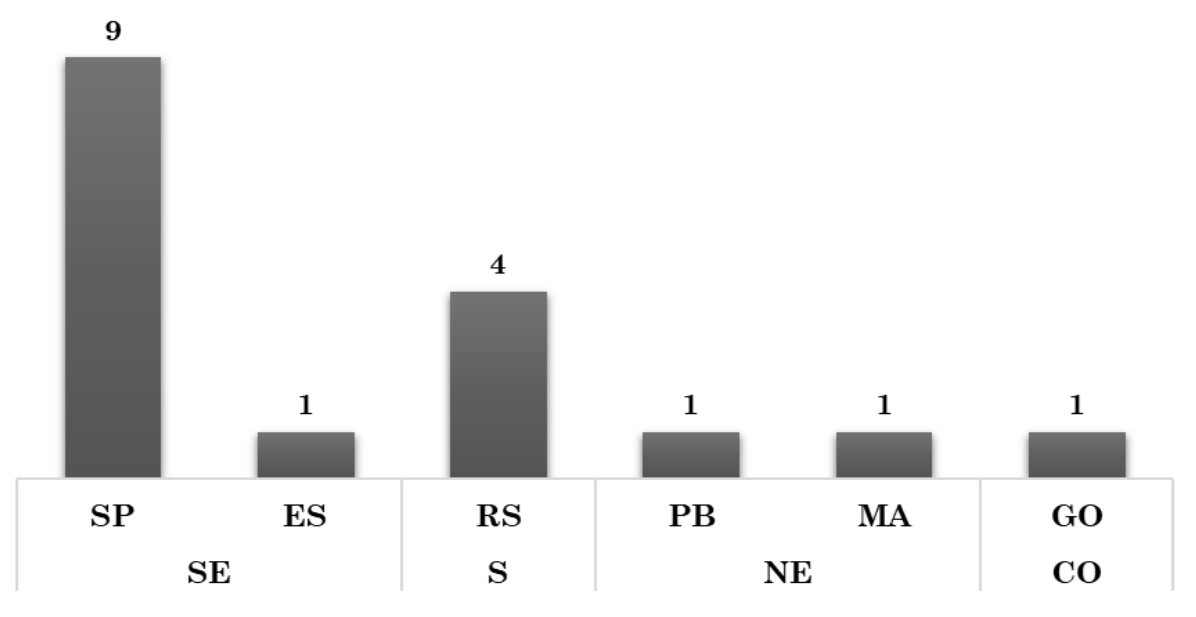

Fonte: Autoria própria

Em observação aos gráficos 1 e 2, considerando os critérios de exclusão utilizados para seleção, verificou-se que ao longo dos cinco anos analisados o número de trabalhos que discutiram "educação e cidadania" foi aproximado, variando entre 2 a 5, com destaque para 2018 que teve 5 trabalhos.

Ademais, o Sudeste do Brasil foi a região com o maior número de trabalhos, sendo o Estado de São Paulo responsável por 90\% do total da região e mais de 50\% do total de trabalhos de todo o país. Interessante notar que, no período analisado, a região Norte não publicou nenhum trabalho quanto à categoria em análise.

Gráfico 3 - Distribuição dos trabalhos por instituição de origem

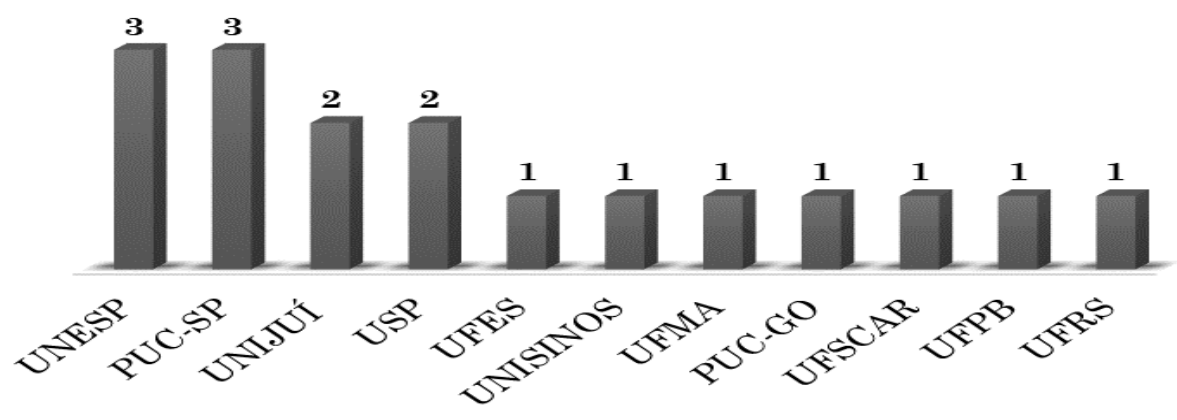

Fonte: Autoria própria 
Conforme gráfico 3, a Universidade Estadual Paulista e a Pontifícia Universidade Católica de São Paulo foram as Instituições com maior número de publicações, seguidas da Universidade Regional do Noroeste do Estado do Rio Grande do Sul e da Universidade de São Paulo.

Gráfico 4 - Distribuição dos trabalhos por tipo de publicação e por curso

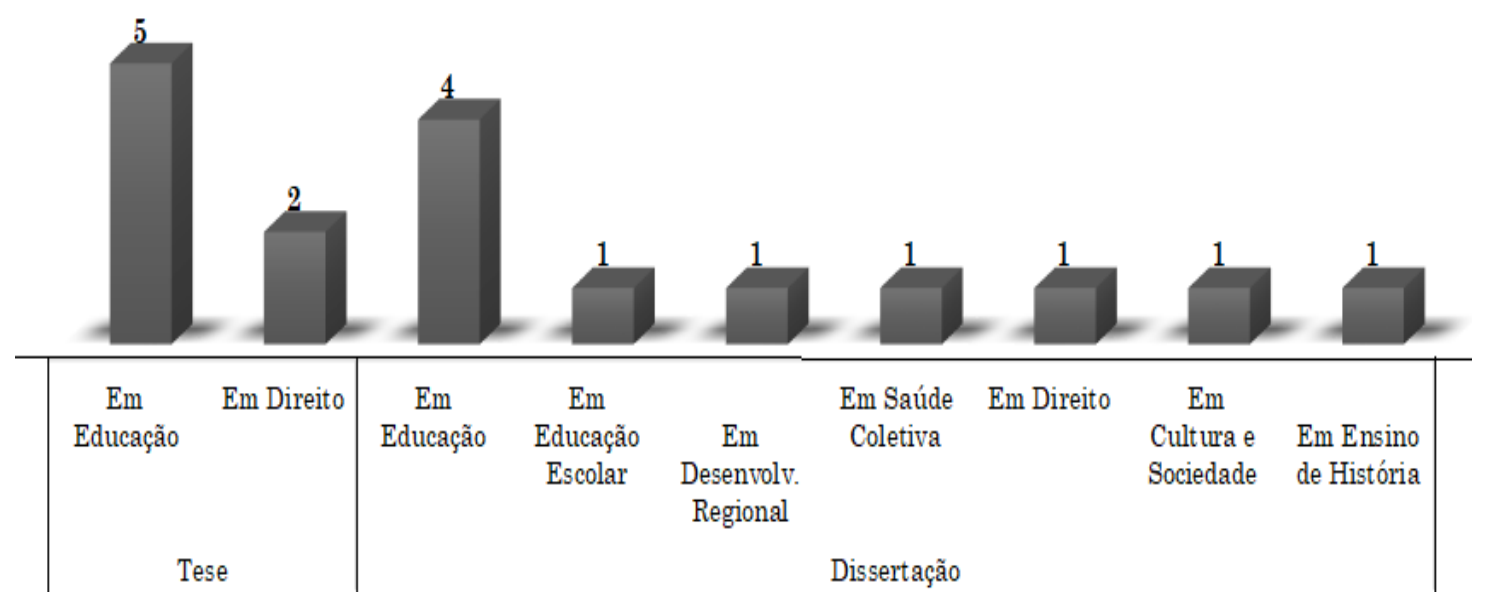

Fonte: Autoria própria

Conforme gráfico 4, mais de $50 \%$ dos trabalhos concentram-se em cursos de doutorado e mestrado em Educação, além do mestrado em Educação Escolar. Em segundo lugar, ficaram os cursos na área de Direito, sendo dois doutorados e um mestrado. Destacamos dois cursos de mestrado, quais sejam: em Cultura e Sociedade e em Saúde Coletiva, uma vez que apesar de serem em áreas distintas apresentaram a temática educação e cidadania em suas pesquisas.

Em relação à abordagem metodológica, as pesquisas em sua maioria foram qualitativas, sendo apenas duas quali-quantitavas. Quanto ao tipo, predominaram as pesquisas bibliográficas e documentais. Ainda, os trabalhos apresentaram aproximações quanto ao referencial teórico. De modo geral, identificou-se que 11 dos 17 trabalhos citaram a autora Hannah Arendt. Isso se explica, uma vez que "o conceito de cidadania para Hannah Arendt está exclusivamente relacionado à participação política na esfera 
decisória de poder (esfera pública), na qual o cidadão é denominado "ser político" (SCHÜTZ, 2016, p. 7).

Do forma semelhante, o autor Paulo Freire foi citado em 12 trabalhos, tendo em vista que este autor "incentiva a educação libertadora, crítica, e problematizadora da realidade social, em que a pessoa não aceita simplesmente a ordem social e política vigente, mas escreve sua própria história e a de seu país." (COSTA, 2016, p. 166).

Para fechar essa primeira parte do artigo, seguem abaixo as referências dos trabalhos selecionados, organizadas por região do Brasil (da região com o maior número de trabalhos para a de menor número) e por ano (do mais antigo para o mais atual). Dessa forma, será possível visualizar de forma consolidada os dados de cada dissertação ou tese que foram fragmentados para elaboração dos gráficos acima apresentados.

Quadro 1 - Dissertações e teses selecionadas

\begin{tabular}{|c|l|}
\hline \multicolumn{2}{|c|}{ REGIÃO SUDESTE } \\
\hline $\mathbf{N}^{\mathbf{o}}$ & \multicolumn{1}{c|}{ Referência } \\
\hline 1 & $\begin{array}{l}\text { GOMES, Leonardo Teixeira. Cidadania e práticas escolares: as representações de um } \\
\text { grupo de alunos do ensino médio de uma escola pública paulista. 2014. 117 f. Dissertação } \\
\text { (Mestrado em Educação Escolar) - Universidade Estadual Paulista Júlio de Mesquita } \\
\text { Filho, Faculdade de Ciências e Letras - Campus de Araraquara, Araraquara, 2014. }\end{array}$ \\
\hline 2 & $\begin{array}{l}\text { LISBOA, Edgar Andrade. Conselhos Locais de Saúde: caminhos e (des)caminhos da } \\
\text { participação social no Sistema Único de Saúde. 2014, 101 f. Dissertação (Mestrado } \\
\text { em Saúde Coletiva) - Programa de Pós-Graduação em Saúde Coletiva, Universidade }\end{array}$ \\
\hline 3 & $\begin{array}{l}\text { Federal do Espírito Santo, Vitória, 2014. } \\
\text { Mo Brasil do início do século XXI. 2014. 234 f. Tese (Doutorado em Direito) - } \\
\text { Pontifícia Universidade Católica de São Paulo, São Paulo, 2014. }\end{array}$ \\
\hline 5 & $\begin{array}{l}\text { CARVALHO, Jaciara de Sá. Educação cidadã a distância: uma perspectiva } \\
\text { emancipatória a partir de Paulo Freire. 2015. 211 f. Tese (Doutorado em Educação) } \\
\text { - Faculdade de Educação da Universidade de São Paulo, São Paulo, 2015. }\end{array}$ \\
\hline 5 & $\begin{array}{l}\text { DIAS, Adriana Marques Guimarães. Gestão democrática, educação e cidadania: um } \\
\text { olhar crítico a partir de fontes bibliográficas. 2015. 180 f. Tese (Doutorado em } \\
\text { Educação) - Universidade Estadual Paulista Júlio de Mesquita Filho, Faculdade de } \\
\text { Ciencias e Letras - Campus de Araraquara, Araraquara, 2015. }\end{array}$ \\
\hline \multirow{2}{*}{$\begin{array}{l}\text { STERING, Silvia Maria dos Santos. O desafio da qualificação para o trabalho na } \\
\text { perspectiva do Proeja no IFMT: Política, fato e possibilidades. 2015. 323 f. Tese } \\
\text { (Doutorado em Educação) - Universidade Estadual Paulista, Instituto de } \\
\text { Biociências de Rio Claro, Rio Claro, 2015. } \\
\text { COSTA, Valquíria Ortiz Tavares. Cidadania: a educação em direitos a emancipação política } \\
\text { Graduados em Direito, Pontifícia Universidade Católica de São Paulo, São Paulo, 2016. }\end{array}$} \\
\hline
\end{tabular}




\begin{tabular}{|c|l|}
\hline \multirow{8}{*}{8} & $\begin{array}{l}\text { TEIXEIRA, Maria Cristina. Educação para a cidadania, fundamento do estado } \\
\text { democrático de direito. 2016. 168 f. Tese (Doutorado em Direito) - Programa de } \\
\text { Estudos Pós-Graduados 0065m Direito, Pontifícia Universidade Católica de São } \\
\text { Paulo, São Paulo, 2016. }\end{array}$ \\
\hline DOMINGUES, Tiago César. Educação e cidadania: aspectos legais, concepções e \\
processos pedagógicos desenvolvidos na ETEC de Piedade-SP à luz de Gramsci. \\
2017. 200 f. Dissertação (Mestrado em Educação) - Universidade Federal de São \\
Carlos, Sorocaba, 2017.
\end{tabular}

Fonte: Autoria própria

\section{Achados qualitativos da pesquisa}

Nessa etapa de aprofundamentos dos trabalhos selecionados, conforme Ferreira (2002), o pesquisador procura responder, além das perguntas "quando", “onde" e "quem”, àqueles questionamentos relativos à "o quê" e "o como" dos trabalhos. 
Para tanto, Ferreira (2002) relata que o pesquisador enfrenta diversas dificuldades, como por exemplo, resumos de trabalhos que são mal elaborados ou incompletos, havendo, assim, a necessidade de acessar a pesquisa na íntegra.

Assim sendo, de um modo geral foram realizadas leituras dos resumos, introduções e conclusões das pesquisas, para identificar as problemáticas, os resultados e outras observações pertinentes. A princípio, serão apresentadas, conforme "Quadro 2", as abordagens dos trabalhos selecionados, considerando a mesma ordem de apresentação dos trabalhos dispostos no "Quadro 1" e, logo em seguida, as análises de cada tese e dissertação.

Quadro 2 - Trabalhos e suas abordagens

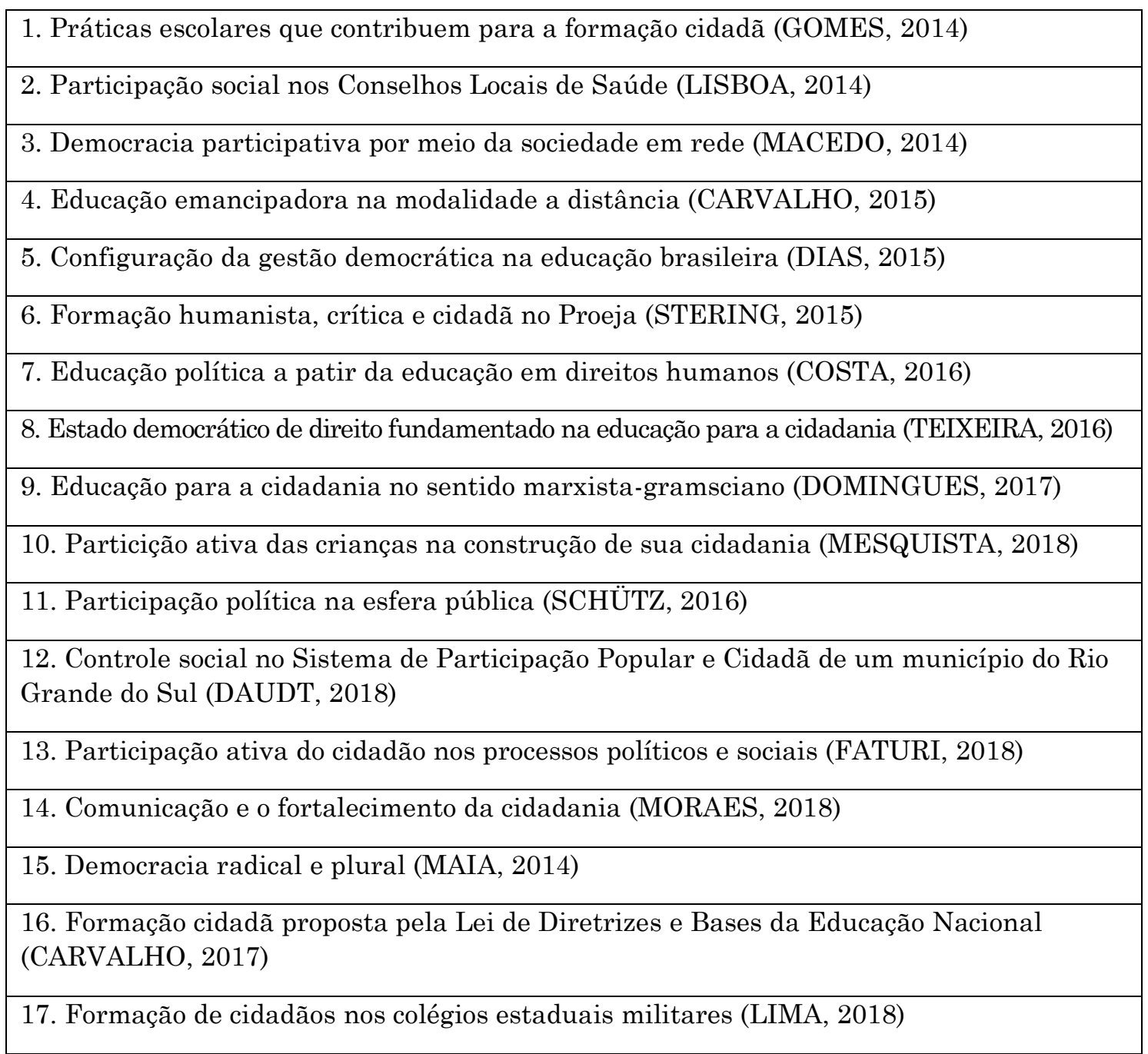

Fonte: Autoria própria 
Gomes (2014), em sua dissertação, buscou identificar quais as representações sociais dos estudantes sobre as práticas escolares que contribuem ou não para a formação cidadã. Ao final, o autor percebe que o conceito de cidadania ainda é abstrato para os estudantes participantes da pesquisa, bem como são poucos os espaços em que eles podem usufruir da prática de uma formação cidadã.

A dissertação de Lisboa (2014) apresentou os conselhos de saúde como canais essenciais de participação social. Em sua conclusão, o autor afirmou, dentre outras coisas, que a participação social e a democracia são imprescindíveis para a construção de políticas de saúde que correspondam às reais necessidades da comunidade. Além disso, ele afirma a relevância dos programas de educação para cidadania dos sujeitos envolvidos nesses espaços de participação.

Por sua vez, a tese de Macedo (2014), que tratou sobre educação, cidadania e democracia, concluiu que para resgatar os valores democráticos é preciso promover a participação dos cidadãos e fazê-los compreender que além da adesão são necessários a reciprocidade e o comprometimento com os direitos de todos e com os desígnios do Estado. Para tanto, é imprescindível desenvolver o capital social (conexões entre os indivíduos / sociedade em rede) por meio de uma educação voltada para a cidadania.

Macedo (2014) nos apresentou um assunto bastante atual, a sociedade em rede. De acordo com o autor, essa ferramenta, resultado da era da informação, possibilita a divulgação e esclarecimento de direitos, amplia os debates e as manifestações de opiniões, permite a integração dos cidadãos para atuarem em objetivos comum.

Carvalho (2015) discutiu em sua tese as condições e os desafios da formação para cidadania na educação a distância. A autora chegou a conclusão de que os desafios para uma formação cidadã não é uma questão de modalidade e sim de enfrentamento de práticas e princípios contrárias ao processo de conscientização pelos sujeitos. 
Dias (2015), em sua tese, versou sobre a configuração da gestão democrática na educação brasileira. A autora concluiu que a concepção da gestão democrática não conseguiu êxito na sociedade brasileira, uma vez que foi reduzido o espaço público e ampliado o privado, por meio da implementação da política neoliberal no Brasil. Dessa forma, a gestão democrática reduziu-se à gestão escolar, assemelhando-se a administração empresarial.

$\mathrm{Na}$ tese de Stering (2015) houve a defesa da ideia de que Programa de Integração da Educação Profissional ao Ensino Médio na Modalidade de Educação de Jovens e Adultos (Proeja) desenvolve uma formação humanista, crítica e cidadã. Dessa forma, a autora apresentou que o Proeja antes de possiblitar a inserção do homem no mercado de trabalho, permite que o sujeito tenha consciência de sua capacidade para agir e transformar o espaço onde vive.

Por sua vez, a dissertação de Costa (2016) teve como temática central a construção da cidadania ativa a partir da educação em direitos humanos. A autora apresentou que esta educação tem dentre suas finalidades instruir o indivíduo nos direitos políticos numa perspectiva participativa. Assim, o trabalho mostrou que o exercício da cidadania só é viabillizado pela educação, uma vez que o indivíduo se apropria do conhecimento necessário para lutar pelos seus direitos e cumprir seus deveres.

A tese de Teixeira (2016) destacou a questão relativa à efetividade de normas constitucionais no que concerne ao princípio do Estado Democrático de Direito e aos direitos fundamentais à educação e à cidadania. A partir disso, a autora defendeu que a educação para o exercício da cidadania é imprescindível para o estabelecimento do Estado Democrático de Direito.

Domingues (2017), em sua dissertação, buscou identificar, a partir do referencial teórico utilizado, como a temática cidadania se apresenta nos normativos legais que norteiam a organização dos sistemas de ensino e os processos educativos do ensino médio e técnico-profissionalizante, bem como no Projeto Político Pedagógico da unidade escolar pesquisada.

Em seu estudo, o autor possibilitou um aprofundamento sobre a diferença da concepção de cidadania no sentido liberal e no sentido marxista- 
gramsciano. Este último sentido, resulta num processo de formação para a cidadania a partir de uma estrutura material e imaterial que dê condições de desenvolvimento da autonomia, visto que o sujeito pode ou não desenvolver autonomia crítica a depender dos processos pedagógicos que o envolvem.

Ademais, de acordo com Domingues (2017), um cidadão, na condição de governado, deve possuir, mesmo que de forma abstrata, as plenas capacidades de um governante, de modo que entenda as estruturas de poder, historicamente formadas, e sua função social.

Por sua vez, Mesquita (2018) investigou, em sua tese, as possibilidades do exercício da cidadania desde a infância no âmbito da escola pública, a partir da participação das crianças em decisões sobre assuntos de seus interesses. Como resultado, a autora concluiu que é completamente viável a realização de propostas na educação que possibilitem à criança a participação ativa na construção de sua cidadania. Para tanto, de acordo com a autora é necessário romper com a estrutura tradicional de ensino, uma vez que se aprende a cidadania exercendo-a.

Schütz (2016), em sua dissertação, analisou a relação existente entre a educação e o conceito de cidadania. Para tanto, buscou-se compreender, especialmente, o conceito de cidadania elaborado por Hannah Arendt em suas obras. Conforme o autor, a partir das conclusões de Arendt, a cidadania é uma dimensão do agir político e, dessa forma, não há cidadania sem participação política.

A dissertação de Daudt (2018) tratou sobre os espaços de controle social do Sistema de Participação Popular e Cidadã do município de CanoasRS. Os resultados da pesquisa apontaram, no processo de educação para a cidadania através da participação popular, para a importância do senso de coletividade nos espaços de controle social.

Faturi (2018), em sua dissertação, buscou examinar as compreensões dos jovens sobre a cidadania e o papel da escola e do ensino de História nesse processo. O autor inferiu que para a construção de uma sociedade democrática é necessário fornecer, por meio da educação, as condições 
intelectuais, materiais e sociais para que os estudantes compreendam e possam intervir de forma ativa nos processos políticos e sociais que os cercam.

A dissertação de Moraes (2018) apresentou que a comunicação, como prática educativa, é essencial para o fortalecimento da cidadania. A autora defendeu que o rádio é democrático e institui relações cidadãs entre seus componentes, uma vez que possibilita a pluralidade de vozes. Assim, a partir dessa ferramenta os estudantes passam a debater e abordar temáticas importantes para o desenvolvimento da cidadania e aprimoramento de suas capacidades sociais.

Por sua vez, a tese de Maia (2014) evidenciou a comparação dos sentidos de cidadania a partir dos discursos de alunos, docentes e documentos curriculares no âmbito da disciplina de sociologia. Ao final, a autora sugeriu algumas implicações dos sentidos de cidadania que podem contribuir para o surgimento de cidadãos participativos, especialmente na área política, e que podem ser relevantes para o fortalecimento das formas de democracia radical e plural.

A dissertação de Carvalho (2017) teve como objetivo principal investigar no pensamento rousseauniano os princípios sobre educação e cidadania desenvolvendo uma comparação crítico-reflexiva com o ideal de cidadania proposto pela Lei de Diretrizes e Bases da Educação Nacional (LDB $\mathrm{n}^{\circ}$ 9394/1996). Dessa forma se estabeleceu uma crítica ao cumprimento dessa Lei, quanto à formação cidadã, diante da realidade escolar, tendo em vista que, conforme o autor, o processo educativo perdará sua relevância se não idealizar a formação do cidadão.

Já a dissertação de Lima (2018) teve como finalidade principal identificar se o ensino disciplinar e hierárquico dos colégios estaduais militares de Goiás favorecia a formação de cidadãos participativos, reflexivos e autônomos, ou cidadãos subservientes. Ao final, a autora constatou que os cidadãos formados nesses colégios contribuirão para a perpetuação do sistema capitalista, uma vez que o investimento na 
formação servil possibilita a dominação e a exploração das forças produtivas das classes trabalhadoras.

Lima (2018) conclui que, com a predominância do autoritarismo como forma de administrar suas instituições, os colégios estaduais militares de Goiás representam um retrocesso e uma estagnação para a luta e conquista de uma educação mais democrática.

A autora revela, ainda, que embora estas instituições proclamem uma gestão democrática para formar cidadãos atuantes no processo emancipatório, seus documentos e suas práticas revelam uma gestão centralizadora, disciplinar e hierárquica.

Os trabalhos de Gomes (2014) e Mesquita (2018) refletem sobre a importância de uma educação que prioriza a formação cidadã, por meio da promoção de espaços de participação dos estudantes, dentro e fora da sala de aula, em que exercitem a cidadania crítica e participativa.

Lisboa (2014), Macedo (2014) e Daudt (2018) ao trataraem, de um modo geral, sobre a participação social e política corroboraram com o entendimento de Gadotti (2014, p. 4) quando ele relata: "Nos formamos para a participação participando, enfrentando os desafios técnicos e políticos da participação. A participação é conquista político-pedagógica".

As dissertações de Costa (2016) e Faturi (2018), ao abordarem sobre a interdependência entre educação e cidadania confirmaram a compreensão de Carvalho (2002, p. 11) de que "a ausência de uma população educada tem sido sempre um dos principais obstáculos à construção da cidadania civil e política".

Mediante a reflexão sobre as diferenças entre a concepção de cidadania no sentido marxista-gramsciano e no sentido liberal apresentadas por Domingues (2017), verificou-se que Stering (2015), ao tratar em sua tese sobre o Proeja, demonstrou que esse programa reflete uma concepção de cidadania no sentido marxista-gramsciano.

Por outro lado, o resultado da pesquisa de Lima (2018) refletiu uma concepção de cidadania no sentido liberal, uma vez que constatou que os 
cidadãos formados no colégios estaduais militares de Goiás contribuirão para a perpetuação do sistema capitalista.

No que se refere à temática educação e cidadania articulada aos interesses da juventude, cabe destacar as dissertações de Faturi (2018), Gomes (2014) e Moraes (2018), bem como a tese de Maia (2014), uma vez que realizaram suas pesquisas com foco no público jovem.

Nesse contexto, Faturi (2018) investigou em que medida a escola constrói a juventude e reflete sobre as tensões e ambiguidades vivenciadas pelo jovem, ao se constituir como aluno num ambiente escolar que normalmente desconsidera a sua condição juvenil e cidadã. Essa pesquisa, reforça o entendimento observado por Dayrell, Leão e Reis (2007), no qual a condição de aluno é uma alternativa que poderá ser ou não incorporada pelo jovem.

No que diz respeito à dissertação de Gomes (2014), o autor analisou como a juventude observa o presente, quais suas pretensões para o futuro e qual sua capacidade de atuação, especialmente quanto as suas representações sobre a prática de cidadania na escola.

Essa dissertação ao tratar dos anseios dos jovens, demonstrou a necessidade de se ter uma linguagem em comum com esse público, obsersando a necessidade da instituição escolar e de seus professores abrirem espaços de escuta para a compreensão das identidades e comportamentos da juventude, conforme defende Carrano e Martins (2011).

Já Moraes (2018), ao identificar os benefícios do projeto rádio na escola, observou, dentre outras coisas, que os jovens a partir desse projeto começaram a debater e abordar temáticas importantes para 0 desenvolvimento da cidadania e aprimoramento de suas capacidades sociais.

Essa dissertação ao defender o rádio como uma ferramenta de formação cidadã para os jovens, reconhece a importância de práticas que aproximem os jovens de seus reais interesses e, dessa forma, rompe o afastamento entre a assertiva da reflexão e a vivência de práticas significativas, conforme retratou Dayrell, Leão e Reis (2007). 
Por sua vez, Maia (2014, p. 79) relatou que a "educação para a cidadania ofere ao jovem aluno uma função mais proativa e autônoma no processo educacional e os conhecimentos acerca da cidadania construídos se colocam como instrumentos de transformação social.”.

Desse modo, a autora defendeu que o espaço educacional deve utilizar estratégias para encorajar os jovens estudantes a encontrar caminhos de representação e articulação de suas preocupações e demandas.

Esses trabalhos ao abordarem sobre educação e cidadania articulada aos interesses da juventude fortaleceram o entendimento da importância de se criar, no ambiente escolar, espaços em que os jovens sejam escutados. Deste modo, os estudantes poderão apresentar suas reais necessidades, bem como poderão desenvolver a consciência crítica sobre o papel que ocupam na sociedade.

Por fim, a partir das dissertações e teses analisadas, verificou-se o desafio de se promover estratégias de participação e tomada de decisão que tornem o processo de aprendizagem significativo para estudantes, considerando que a educação viabiliza as condições necessárias para a prática cidadã e que, consequentemente, a cidadania não se concretiza sem a participação social e política.

\section{Conclusão}

Conforme apresentado anteriormente, o presente artigo teve o propósito de identificar as problematizações realizadas no Brasil, nos anos de 2014 a 2018, quanto à temática educação e cidadania, com a finalidade de mapear o estado da arte e apresentar as contribuições dos trabalhos analisados.

Portanto, quanto ao mapeamento do estado da arte, através da quantificação e de identificação de dados bibliográficos, verificou-se que o número de trabalhos ao longo dos cinco anos analisados foi aproximado, variando entre 2 a 5 , o que revelou um número reduzido de pesquisas, denotando a necessidade de novas problematizações quanto ao tema proposto.

A produção acadêmica, na amostra selecionada, está concentrada na região Sudeste do Brasil, com destaque para o Estado de São Paulo que 
corresponde a mais de $50 \%$ do total de trabalhos de todo o país. Quanto à região Norte, no período analisado, não houve nenhuma publicação de trabalho quanto ao tema pesquisado.

Além disso, mais de 50\% dos trabalhos concentraram-se em cursos de doutorado e mestrado em Educação. Em relação à abordagem metodológica, as pesquisas em sua maioria foram qualitativas, sendo apenas duas quali-quantitavas. Quanto ao tipo, predominaram as pesquisas bibliográficas e documentais.

No que concerne às contribuições dos trabalhos analisados, na seção dos achados qualitativos, foram apresentados os objetivos e as principais conclusões das teses e dissertações. De um modo geral, os trabalhos ratificaram a impossibilidade de se exercer a cidadania sem uma educação adequada, ou seja, uma educação que vise ao pleno desenvolvimento da pessoa e seu preparo para o exercício da cidadania, conforme dispõe o art. 205 da nossa Constituição Federal.

Dentre os trabalhos destacaram-se os que refletiram sobre a importância de uma educação que prioriza a formação cidadã, por meio da promoção de espaços de participação dos estudantes, dentro e fora da sala de aula, em que exercitem a cidadania crítica e participativa.

Ainda, as pesquisas confirmaram o entendimento dos autores citados na parte introdutória deste artigo, especialmente, ao abordaram sobre a importância da formação para participação social e política, bem como sobre a intedependência entre educação e cidadania.

Ademais, ao identificar as pesquisas que trataram sobre a temática educação e cidadania articulada aos interesses da juventude, foi possível constatar o reduzido número de trabalhos que se preocuparam em investigar sobre a participação juvenil, especialmente no espaço acadêmico. Dos 17 trabalhos, apenas 3 dissertações e 1 tese realizaram suas pesquisas com foco no público jovem.

Esses trabalhos fortaleceram o entendimento da importância de se criar, no ambiente escolar, espaços em que os jovens sejam escutados. Deste modo, os 
estudantes poderão apresentar suas reais necessidades, bem como poderão desenvolver a consciência crítica sobre o papel que ocupam na sociedade.

Nesse contexto, vale registar que, conforme art. $4^{\circ}$ da Lei $^{\circ} 12.852 / 2013$ (Estatuto da Juventude): "O jovem tem direito à participação social e política e na formulação, execução e avaliação das políticas públicas de juventude." (BRASIL, 2013). Assim sendo, para que o jovem ocupe uma posição central nos processos políticos e sociais, ele precisa desenvolver uma consciência critíca, por meio de espaços pedagógicos que possibilitem a participação, liberdade de opinião e, consequentemente, a formação cidadã.

Portanto, o conjunto dos estudos possibilitou compreender como é basilar a reflexão de que a educação, direito social fundamental, é um requisito essencial para conquista da cidadania política pelos jovens estudantes frente aos desafios da atualidade.

Por fim, diante da revelância social e acadêmica da temática apresentada, espera-se que o presente artigo motive pesquisadores a apresentarem novas problematizações referentes à relação existente entre educação e cidadania, de um modo especial articulada aos interesses da juventude.

\section{Referências}

ALPÍZAR, L.; BERNAL, M. Construção social da juventude: leitura 1, módulo1. In: Mulheres jovens e direitos humanos: manual de capacitação em direitos humanos das mulheres jovens e a aplicação da CEDAW. São Paulo: Edlac, 2005.

BRASIL. Lei $n^{\circ} 13.005$, de 25 de junho de 2014. Aprova o Plano Nacional de Educação - PNE e dá outras providências. Brasília, DF: Presidência da República, [2014]. Disponível em: http://www.planalto.gov.br/ ccivil_03/_ato2011-2014/2014/lei/113005.htm. Acesso em: 21 jul. 2019.

BRASIL. Lei $n^{\circ} 12.852$, de 5 de agosto de 2013. Institui o Estatuto da Juventude e dispõe sobre os direitos dos jovens, os princípios e diretrizes das políticas públicas de juventude e o Sistema Nacional de Juventude SINAJUVE. Brasília, DF: Presidência da República, [2013]. Disponível em: http://www.planalto.gov.br/ccivil 03/ Ato2011-2014/2013/Lei/L12852.htm. Acesso em: 21 jul. 2019. 
BDTD. Biblioteca Digital Brasileira de Teses e Dissertações, 2019. Sobre a BDTD. Disponível em: http://bdtd.ibict.br/vufind/. Acesso em: 31 de jul. de 2019.

CARRANO, P. O ensino médio na transição da juventude para a vida adulta. In: FERREIRA, C. A. Juventude e iniciação científica: políticas públicas para o ensino médio. Rio de Janeiro: EPSJV, UFRJ, 2010.

CARRANO, P.; MARTINS, C. H. S. A escola diante das culturas juvenis: reconhecer para dialogar. Educação, Santa Maria, v. 36, n. 1, p. 43-56, jan./abr. 2011.

CARVALHO, H. V. Rousseau para o século XXI: um olhar filosófico sobre a formação da cidadania a partir da Lei de Diretrizes e Bases da Educação. 2017. 140 f. Dissertação (Mestrado em Cultura e Sociedade) - Universidade Federal do Maranhão, São Luís, 2017. Disponível em:

http://www.pgcult.ufma.br/wp-content/uploads/2017/09/HernaniVeloso.pdf. Acesso em: 4 jul. 2019.

CARVALHO, J. S. Educação cidadã a distância: uma perspectiva emancipatória a partir de Paulo Freire. 2015. 211 f. Tese (Doutorado em Educação) - Faculdade de Educação da Universidade de São Paulo, São Paulo, 2015. Disponível em: http://www.teses.usp.br/teses/disponiveis /48/48134/tde-11052015-100811/pt-br.php. Acesso em: 6 jul. 2019.

CARVALHO, J. M. Cidadania no Brasil. O longo caminho. $3^{\mathrm{a}}$ ed. Rio de Janeiro, Civilização Brasileira, 2002. Disponível em: http://www.do.ufgd.edu.br/mariojunior/arquivos/cidadania_brasil.pdf. Acesso em: 11 abr. 2019.

CAÚ, J. N. A. A juventude do curso técnico integrado em agropecuária do IFPE: desejos, expectativas e experiências vivenciadas para construção do seu projeto de vida. 2017. 398 f. Tese (Doutorado em Educação) Universidade Federal de Pernambuco, Recife, 2017.

COSTA, V. O. T. Cidadania: a educação em direitos a emancipação política do homem. 2016. 205 f. Dissertação (Mestrado em Direito) - Programa de Estudos Pós-Graduados em Direito, Pontifícia Universidade Católica de São Paulo, São Paulo, 2016. Disponível em:

https://tede2.pucsp.br/bitstream/handle/19595/2/Valqu\%c3\%adria\%20Ortiz \%20Tavares\%20Costa.pdf. Acesso em: 5 jul. 2019.

DAYRELL, J.; LEÃO, G.; REIS, J. Juventude, pobreza, e ações sócioeducativas no Brasil. In: SPOSITO, Marilia Pontes (Org.). Espaços públicos e tempos juvenis. São Paulo: Global, 2007. p. 47-82. 
DAUDT, P. F. As dimensões pedagógicas dos espaços do controle social do sistema de participação popular e cidadã do município de Canoas. 2018. 114 f. Dissertação (Mestrado em Educação) - Universidade do Vale do Rio dos Sinos, São Leopoldo, 2018. Disponível em:

http://www.repositorio.jesuita.org.br/bitstream/handle/UNISINOS/7438/Paloma\% 20de\%20Freitas\%20Daudt .pdf?.sequence=1\&isAllowed=y. Acesso em: 7 jul. 2019.

DIAS, A. M. G. Gestão democrática, educação e cidadania: um olhar crítico a partir de fontes bibliográficas. 2015. $180 \mathrm{f}$. Tese (Doutorado em Educação) - Universidade Estadual Paulista Júlio de Mesquita Filho, Faculdade de Ciencias e Letras - Campus de Araraquara, Araraquara, 2015. Disponível em: https://repositorio.unesp.br/bitstream/

handle/11449/126509/000840693.pdf? sequence=1\&isAllowed=y. Acesso em: 4 jul. 2019.

DOMINGUES, T. C. Educação e cidadania: aspectos legais, concepções e processos pedagógicos desenvolvidos na ETEC de Piedade-SP à luz de Gramsci. 2017. 200 f. Dissertação (Mestrado em Educação) - Universidade Federal de São Carlos, Sorocaba, 2017. Disponível em:

https://repositorio.ufscar.br/handle/ufscar/9199?show=full. Acesso em: 5 jul. 2019.

FATURI, F. R. Cidadania: da reflexão à prática. Contribuições do ensino de história. 2018. 143 f. Dissertação (Mestrado Profissional de Ensino de História) Universidade Federal do Rio Grande do Sul, Porto Alegre, 2018. Disponível em: https://lume.ufrgs.br/handle/10183/185983. Acesso em: 6 jul. 2019.

FERREIRA, N. S. A. As pesquisas denominadas "Estados da Arte". Educação \& Sociedade, Campinas, n. 79, v. 23, p. 257-272, ago. 2002. Disponível em: http://www.scielo.br/pdf/es/v23n79/10857.pdf. Acesso em: 31 ago. 2019.

GADOTTI, M. História das ideias pedagógicas. São Paulo: Ática, 1993.

GADOTTI, M. Gestão democrática com participação popular no planejamento e na organização da educação nacional. Brasília: MEC, 2014. Disponível em:

http://conae2014.mec.gov.br/images/pdf/artigogadotti_final.pdf. Acesso em: 20 jun. 2020.

GIL, A. C. Métodos e técnicas de pesquisa social. 6. ed. São Paulo: Atlas, 2008.

GOMES, L. T. Cidadania e práticas escolares: as representações de um grupo de alunos do ensino médio de uma escola pública paulista. 2014. 117 f. Dissertação (Mestrado em Educação Escolar) - Universidade Estadual Paulista Júlio de Mesquita Filho, Faculdade de Ciencias e Letras - Campus de Araraquara, Araraquara, 2014. Disponível em: https://repositorio.unesp.br/handle/11449/115574. Acesso em: 5 jul. 2019. 
LIMA, M. E. A educação para a cidadania e a militarização para a educação. 2018. 187 f. Dissertação (Mestrado em Educação) - Pontifícia Universidade Católica de Goiás, Goiânia, 2018. Disponível em:

http://tede2.pucgoias.edu.br:8080/bitstream/tede/4051/2/Maria\%20Eliene $\% 2$ 0Lima.pdf. Acesso em: 9 jul. 2019.

LISBOA, E. A. Conselhos Locais de Saúde: caminhos e (des)caminhos da participação social no Sistema Único de Saúde. 2014, 101 f. Dissertação (Mestrado em Saúde Coletiva) - Programa de Pós-Graduação em Saúde Coletiva, Universidade Federal do Espírito Santo, Vitória, 2014. Disponível em: http://repositorio.ufes.br/bitstream/10/1079/1/Dissertacao\%20Edgar\% 20Andrade\%20Lisboa.pdf. Acesso em: 7 jul. 2019.

MACEDO, C. S. Educação, cidadania e reflexão sobre a democracia no Brasil do início do século XXI. 2014. 234 f. Tese (Doutorado em Direito) Pontifícia Universidade Católica de São Paulo, São Paulo, 2014. Disponível em: https://tede2.pucsp.br/bitstream/handle/6474/1/Caio\%20 Sperandeo\%20de\%20Macedo.pdf. Acesso em: 4 jul. 2019.

MAIA, A. A. M. Educação para a cidadania no ensino médio: uma aproximação das articulações discursivas de alunos, docentes e documentos curriculares no âmbito da sociologia. 2014. 224 f. Tese (Doutorado em Educação) - Universidade Federal da Paraíba, João Pessoa, 2014. Disponível em:

https://repositorio.ufpb.br/jspui/handle/tede/4785. Acesso em: 6 jul. 2019.

MARCONI, M. A.; LAKATOS, E. M. Metodologia do trabalho científico. 7. ed. São Paulo: Atlas, 2011.

MESQUITA, D. L. O exercício da cidadania desde a infância como inédito viável: saberes e sabores da experiência na EMEF Presidente Campos Salles. 2018. 267 f. Tese (Doutorado em Educação) - Faculdade de Educação, Universidade de São Paulo, São Paulo, 2018. Disponível em:

http://www.teses.usp.br/teses/disponiveis/48/48134/tde-14122018-085630/ptbr.php. Acesso em: 9 jul. 2019.

MORAES, P. A. O que está no ar? o rádio em escolas do noroeste gaúcho: educomunicação para a cidadania. 2018. 116 f. Dissertação (Mestrado em Desenvolvimento Regional) - Universidade Regional do Noroeste do Estado do Rio Grande do Sul - Campus Ijuí, Ijuí, 2018. Disponível em: http://bibliodigital.unijui.edu.br:8080/xmlui/bitstream/handle/123456789 15782/P\%c3\%a2mela\%20Andrade\%20de\%20Moraes.pdf?sequence=1. Acesso em: 7 jul. 2019.

KRAWCZYK, N. Uma roda de conversa sobre os desafios do ensino médio. In: DAYRELL, Juarez; CARRANO, Paulo; MAIA, Carla Linhares (Org.). Juventude e ensino médio: sujeitos e currículos em diálogo. Belo Horizonte: UFMG, 2014. p 75-98. 
OLIVEIRA, A. R. Marx e a exclusão. Pelotas: Seiva, 2004.

PACHECO, E. Fundamentos Político-Pedagógicos dos Institutos Federais: diretrizes para uma educação profissional e tecnológica transformadora. Natal: IFRN, 2015. Disponível em:

https://memoria.ifrn.edu.br/bitstream/handle/1044/1018/Fundamentos\%20P oli\%CC\%81tico-Pedago\%CC\%81gicos\%20dos\%20Institutos $\% 20$ Federais $\% 20$ \%20Ebook.pdf? sequence =1\&isAllowed=y. Acesso em: 10 ago. 2019.

STERING, S. M. S. O desafio da qualificação para o trabalho na perspectiva do Proeja no IFMT: política, fato e possibilidades. 2015. 323 f. Tese (Doutorado em Educação) - Universidade Estadual Paulista, Instituto de Biociências de Rio Claro, Rio Claro, 2015. Disponível em:

https://repositorio.unesp.br/bitstream/handle/11449/138556/000860836.pdf?s equence=1\&isAllowed=y. Acesso em: 4 jul. 2019.

SCHÜTZ, J. A. Educação e cidadania: reflexões à luz de Hannah Arendt. 2016. 94 f. Dissertação (Mestrado em Educação) - Universidade Regional do Noroeste do Estado do Rio Grande do Sul, Ijuí, 2016. Disponível em:

http://bibliodigital.unijui.edu.br:8080/xmlui/bitstream/handle/123456789/5046/Je nerton\%20Arlan\%20Sch\%c3\%bctz.pdf?sequence=1. Acesso em: 8 jul. 2019.

TEIXEIRA, M. C. Educação para a cidadania, fundamento do estado democrático de direito. 2016. 168 f. Tese (Doutorado em Direito) - Programa de Estudos Pós-Graduados em Direito, Pontifícia Universidade Católica de São Paulo, São Paulo, 2016. Disponível em:

https://repositorio.unesp.br/handle/11449/138556. Acesso em: 4 jul. 2019. 